\title{
Analysis rates of drunk driving accidents and temporal distribution between 2012 and 2016 and risk factors
}

Mei Shen ( $\square$ shmei3@126.com )

Walker County Public School District

Yue Du

Southern Medical University

Hua sheng Zhou

Southern medical University

Research article

Keywords: forensic science; drunk driving; collisions; temporal distribution; risk factors

Posted Date: September 12th, 2019

DOI: https://doi.org/10.21203/rs.2.14376/v1

License: (c) This work is licensed under a Creative Commons Attribution 4.0 International License.

Read Full License 


\section{Abstract}

Background: This study aimed to understand the temporal distribution characteristics of road traffic collisions and the drunk driving collisions and casualty rates in some districts of Guangzhou city to develop suggestions for prevention of drunk driving.

Methods: Data such as test results, casualties, and occurrence time from a total of 4986 traffic collisions reports issued by the Health Laboratory Centre of Southern Medical University between 2012 and 2016 were retrospectively analyzed.

Results: Outcome measures included the relationship between the temporal distribution and rate of drunkdriving collisions and casualties. Data from the recent five years indicated that the number of collisions declined yearly, and the detection detection rate of drunk driving increased yearly. Drunk driving collisions mainly occurred during the period from 22:00-04:00 every day. The number of traffic collisions and the detection rate of drunk driving were significantly higher in the nighttime than that in the daytime. Most collisions occurred on Wednesday. The detection rate of drunk driving collisions was high in February, October, November and December, all with a percentage of more than $63 \%$. The casualty rate of collisions that did not involve drunk driving was significantly higher than that of drunk driving collisions.

Conclusion: Through the analysis of drunk driving in some districts of Guangzhou, we can control the intensity of drunk driving inspection so as to prevent road traffic collisions caused by drunk driving. At the same time, the government should step up publicity and education on the hazards of drunk driving to reduce the occurrence of drunk driving Road traffic collisions.

\section{Background}

Road traffic injury $\mathbb{R T} \mathbb{Q}$ is an important public health problem worldwide. The Global Burden of Disease Study indicated that 1,060,000 people died due to road traffic injuries worldwide in 2003[1-5]. According to data from China's Ministry of Public Security Traffic Management Bureau, at the end of 2016, there were 194,400,000 civilian vehicles in China, including 8,810,000 three-wheeled automobiles and lowspeed trucks, in the country. This was an increase of $73,510,000$ vehicles as compared to the number in 2012 (120,890,000 vehicles). There were 2,300,000 civilian vehicles in Guangzhou, China [6]. The huge number of motor vehicles and drivers has created heavy traffic and a huge challenge for the traffic safety management. The huge number of motor vehicles and drivers has created heavy traffic and a huge challenge for the traffic safety management. A sound body of scientific evidence indicates that drunk driving increases the risk of being involved in traffic crashes, as well as the severity of resulting injuries[7-9]. Liu et al. suggested that detection rate of drunk driving collisions was 4.13 times higher than that of non-drunk driving collisions[10]. Stringent laws and regulations have been introduced in some countries to reduce the rate of drunk driving[11-14]. Since 2004, the Chinese government has adopted increasingly stricter policies and laws to combat drunk driving. 5 The landmark 8th Amendment 
to the Criminal Code enacted by the National People's Congress criminalized drunk driving beginning on May 1, 2011. According to the amended law, those who drive a motor vehicle with a BAC between 20 and $79 \mathrm{mg} / \mathrm{dL}$ will be punished by the public-security bureau, including suspension of the driver's license for at least 6 months and pay a fine. Those who drink and drive with a BAC greater than $80 \mathrm{mg} / \mathrm{dL}$ will lose their license for at least 5 years and will face prosecution for criminal offenses[15].

There are differences in the epidemiological characteristics of road traffic collisions in different regions due to different natural environments and social living conditions, which are correlated with culture, living habits, laws and regulations, and economic level [16-18]. Hingson R et al. studies have shown that drunk driving is more likely to be accompanied by traffic safety hazards such as speeding, non-use of protective measures, and the lane control power is also significantly reduced. With the increase of ethanol content in driver's blood, the probability of these violations is higher[19]. Drinking can affect people's ability of thinking, judgment and coordination of movement, and there are obvious differences between the driver's driving behavior after drinking and that without drinking. The ability to cope with stress after drinking is also affected. Correct and rapid response measures can not be taken after the conflict occurs to mitigate the harm of the accident. Thus, drunk driving may be a primary cause of road traffic collisions. Currently, investigations regarding drunk driving have been undertaken in most countries [20-24], and in general, alcohol breath testing is used first to determine if a driver is drunk, followed by testing blood alcohol concentration (BAC). BAC was used to decide drunk driving behavior.

However, there are few studies on the analysis rates of drunk driving collisions and temporal distribution. This study assessed the relationship between blood alcohol concentration and time distribution, including distribution by month, distribution by weekday, distribution by daytime and nighttime, distribution by periods in a day, distribution by work days and non-work days. The purpose was to examine the correlation between the temporal distribution of drunk driving and the number of traffic collisions and casualties in recent five years in some districts of Guangzhou city to provide data that deepening people's understanding of drinking harmful to traffic safety and may be helpful for preventing road traffic collisions caused by drunk driving.

\section{Methods}

\section{Materials}

As the provincial capital of Guangdong Province, Guangzhou is located in the southern part of Mainland China.Guangzhou has long been one of the most crowded cities in China. There are 11 districts in Guangzhou, China. Data from 4986 collision reports from 8 districts of Guangzhou city issued by the Hygiene Detection Centre of Southern Medical University between January 01, 2012 and December 31, 2016 were retrospectively analyzed.These 8 districts are the main metropolitan areas of Guangzhou and they are densely populated and have many vehicles. In addition, according to the case information provided by the police, data such as occurrence time, casualties, and BAC were extracted and statistical analysis was performed. 


\section{Ethical statement}

The study is in compliance with the Declaration of Helsinki as described in principle 24-"Privacy and Confidentiality".

\section{Investigation methods}

In order to analyze the relationship between different time distribution and drunk driving collisions, we classify the time. The data were divided in a number of ways: 1) Grouping by year, each year as a group; 2) Grouping by month; 3 ) Grouping by each day (Monday to Sunday); 4) Grouping by daytime (am 7:00 to pm 7:59) and nighttime (pm 20:00 to am 6:59); 5) Grouping by every 2 hours period; 6) Grouping by work days and public holidays (national legal public holidays and weekends [non-work days]). Data were analyzed to obtain correlations between the temporal distribution of road traffic accidences, drunk driving rate, accident rate, and casualties.

\section{Determination of BAC and standards}

All police inspect according to the requirements of road traffic inspection. In order to rule out drunk driving, the blood alcohol concentration of drivers in traffic accidents was examined. Blood was collected by two police officers in a regular hospital and sent to the Forensic Center of Southern Medical University for GC-MS testing. Forensic technical specification SF/Z JD0107001-headspace gas chromatography of blood ethyl alcohol detection (2016 version) and the Public Safety Industry Standards of the People's Republic of China GA/T842 blood alcohol concentration detection method (2009 version) were used to test BAC.

National standards (GB19522-2010) of the Vehicle Driver's blood [25], Breath Alcohol Content Threshold and Inspection issued by the General Administration of Quality Supervision, Inspection and Quarantine of the People's Republic of China state that $20 \mathrm{mg} / 100 \mathrm{~mL} \leq \mathrm{BAC}<80 \mathrm{mg} / 100 \mathrm{~mL}$ is considered as driving after drinking, and $B A C \geq 80 \mathrm{mg} / 100 \mathrm{~mL}$ is considered driving drunk. In this study, $B A C<20 \mathrm{mg} / 100 \mathrm{~mL}$ was considered non-drunk driving and $B A C \geq 20 \mathrm{mg} / 100 \mathrm{~mL}$ was considered drunk driving.

\section{Statistical analysis}

Excel software was used to establish the database. Analysis of variance and chi-square test were applied for examining the data. All analyses were performed with SPSS version 20 software.

\section{Results}

\section{Overall conditions}

The number of blood samples of drivers involved in traffic collisions in the years from 2012 to 2016 was $1142,1,041,1,057,1,000$, and 746 , respectively. Of them, the number with $B A C \geq 20 \mathrm{mg} / 100 \mathrm{~mL}$ for the same years were 645 (56.6\%), 578 (55.5\%), 604 (57.1\%), 649 (64.9\%), and 526 (70.5\%), respectively. The 
average detection rate of the five years was $60.2 \%$. One-way analysis of variance of collisions of each year suggested that collisions in 2016 were significantly different from those in the other four years, while there were no significant differences in collisions between the years from 2012 to 2015. Chi-square test of the detection rate of collisions of the five years showed that the difference was statistically significant $\left(\chi^{2}\right.$ $=62.538, \mathrm{P}<0.01)$. The analysis of the five years' data showed that there were at least 1,506 deaths, and at least 1,902 people injured due to drunk driving collisions. The overall number of collisions declined yearly, but the number of casualties did not vary significantly. The number of drunk driving collisions decreased yearly (Table 1 ).

\section{Temporal distributions of drunk driving collisions}

Statistical analysis of all data for five years was carried out according to 12 months. The data of the five years showed that there were more collisions in May, July, and December, but it did not show a significant trend of concentration distribution. The number of collisions was the greatest in May; 483 collisions accounting for $9.7 \%$ of the total. The number of collisions was the fewest in February; 305 collisions accounting for $6.1 \%$ of the total. The detection rate of drunk driving was the highest in February, and accounted for $64.9 \%$ of the collisions in the whole month. The detection rate of drunk driving was the lowest in June, accounting for $55.2 \%$ of the collisions in the whole month. Chi-square test was performed to examine the drunk driving and non-drunk driving collisions that occurred in each month, and the difference was statistically significant $\left(X^{2}=19.478, P<0.05\right)($ Table 1$)$.

Statistical analysis of all data for five years was carried out according to the daily distribution. Over the five years, the daily distribution was similar. The number of collisions was the greatest on Sunday; 802 collisions accounting for $16.1 \%$ of the total. The number of collisions was the least on Monday; 632 collisions accounting for $12.7 \%$ of the total. The rate of driving drunk was highest on Wednesday (64\%). The detection rate of drunk driving was lowest on Monday (56.3\%). Chi-square test revealed there was no statistical differences in the number of collisions for each day of the week $\left(\chi^{2}=10.655, P>0.05\right)$ (Table 1).

Statistical analysis of all data for five years was carried out according to the daytime and nighttime. There were 1,458 collisions in the daytime $(29.3 \%)$ and 3,512 in the nighttime $(70.7 \%)$. The drunk driving rate was $37.4 \%$ in the daytime, and was $69.5 \%$ in the nighttime, and the nighttime rate was 1.86 times higher than the daytime rate. Chi-square test was performed to examine the number of drunk driving and non-drunk driving collisions that occurred in the daytime and nighttime, and the difference was statistically significant $\left(\chi^{2}=43.315, P<0.05\right)($ Table 1$)$.

The 4,969 collisions in the five years were divided into groups per every 2 hours, and there was an obvious trend of concentration distribution. The collisions mainly occurred during four periods, 20:0022:00, 22:00-0:00, 00:00-02:00, and 02:00-04:00, with a total of 2,990 collisions accounting for $60.1 \%$ of the total. The most collisions occurred from 22:00-00:00; 814 collisions accounting for $16.4 \%$ of the total. The collisions were the fewest during the period from 10:00-12:00; 145 collisions accounting for 
$2.9 \%$ of the total (Figure 1). The rates of drunk driving were also highest during the aforementioned four periods. The detection rate of drunk driving was the highest during the period from 02:00-04:00 (75.9\%), and lowest during the period from 10:00-12:00 (20.0\%). In addition, there were several break points in the occurrence of drunk driving. The rate during the period from 06:00-08:00 was $60.5 \%$, and during the period from $04: 00-06: 00$ was $35.6 \%$. The detection rate of drunk driving was $37.9 \%$ during the period from 16:00-18:00, while it increased to $63.6 \%$ during the period from 18:00-20:00. There was another small peak during the period from 14:00-16:00. Chi-square test indicated that the non-drunk driving accident rate and the drunk driving accident rate were significantly different $\left(X^{2}=589.923, P<0.05\right)$ (Table 1).

For the highest detection rate of drunk driving in February,every Wednesday and every night from 02:00 to 04:00. In the time distribution period where the detection rate of drunk driving is high, the police should strengthen the inspection of drunk driving in road traffic, control the drivers who cannot drive with blood concentration exceeding BAC ( $\geq 20 \mathrm{mg} / 100 \mathrm{~mL}$ ), and reduce the occurrence of road traffic accidents.

\section{Distribution detection rate of drunk driving by work days and non-work days}

A total of 3,333 collisions occurred during 1,252 work days, with an average of 2.66 collisions per day and a detection rate of drunk driving collisions of $59.8 \%$. A total of 1,653 collisions occurred during 575 non-work days, with an average of 2.87 collisions per day and a detection rate of drunk driving collisions of $60.9 \%$. Chi-square test indicated that the accident rate was not different between the two groups $\left(\chi^{2}=\right.$ $0.551, \mathrm{P}>0.05)$ (Table 1).

The road traffic collisions that occurred during non-work days over the five years were divided by year and month to calculate the number of collisions in each month, and then one-way analysis of variance was performed. The results indicated that there were no differences in drunk driving collisions on non-work days in each month of each year. Pairwise comparison showed that there were only statistical differences between 2012 and 2016, and between 2015 and 2016 (Table 2). There were no statistical differences in the average number of monthly drunk driving collisions on non-work days in each year $(P>0.05)$. Pairwise comparison showed that the difference was not statistically significant (all, $P>0.05$ ). The number of drunk driving collisions that occurred on work days varied significantly (Figure 2).

\section{Accident damage of drunk driving and non-drunk driving}

The number of collisions between 2012 and 2016 in the drunk driving group was 1.51 times greater than in the non-drunk driving group. Of the non-drunk driving collisions, 985 resulted in at least 1,054 deaths, accounting for $19.8 \%$ of the total collisions with an average of 0.53 deaths per accident; while 610 resulted in at least 928 injuries, accounting for $12.2 \%$ of the total collisions with an average of 0.47 injuries per accident. Of the drunk driving collisions, 423 resulted in at least 452 deaths, accounting for $8.5 \%$ of the total collisions with an average of 0.15 deaths per accident; while 648 resulted in at least 648 injuries accounting for $13.0 \%$ of the total collisions with an average of 0.22 injuries per accident. There were 2.33 times more deaths in the non-drunk driving group than in the drunk driving group, and there 
were 0.94 times as many injuries in the non-drunk driving group than in the drunk driving group. Statistical analysis showed that there were significant differences in the death and injury rates between the two groups $\left(\chi^{2}=754.249, P<0.05 ; \chi^{2}=53.134, P<0.05\right)($ Table 3$)$.

\section{Discussion}

According to the World Health Organization (WHO) traffic accident survey, 50\%-60\% of traffic accidents are related to drunk driving, which has been listed as the leading cause of death by WHO.The results of the analysis on data from the period of 2012-2016 showed that the number of collisions decreased yearly. However, the rate of drink-driving collisions increased yearly, which might be because the people who drink do not know the harm of drunk driving, drunk driving, which leads to more traffic crashes of drunk driving.Relevant laws all over the world have stipulated the provisions of restricting drinking and driving in different forms and heavier penalties are imposed on drunk drivers[26-27]. China has now imposed criminal penalties on drunk drivers.

Chinese people have some festivals every year, and the Spring Festival is the most important festival. Every year, the end of January or February is the Spring Festival in China. Everyone has a week's holiday during the Spring Festival. Everyone will have a family gathering at this time. The Spring Festival of 2012-2016 begins at the end of January or February, and the week of vacation is in February. The gathering increased the number of people drinking, so the detection rate of drunk driving increased. In this study, the highest detection rate of drunk driving was found in February. June is the beginning of summer vacation, and there is no long festival in this month. So the number of people who drink has decreased, and the detection rate of drunk driving in June is the lowest. The incidence of road traffic injury in thailand increases is also on the rise during long holiday seasonsI[28]『which is the same as our findings.

In our research, there was statistical difference in detection rate of drunk driving between the two groups, and the detection rate of drunk driving at nighttime was 1.86 times as high as that in the daytime. The results of dividing the data into 2 -hour periods showed that the number of collisions was the greatest in the period from 22:00-00:00, and the detection rate of drunk driving was greatest in two periods: 00:0002:00 and 02:00-04:000. In the current analysis, there were two break points between 04:00-06:00 and 06:00-08:00, and between 18:00-20:00 and 20:00-22:00. It is believe this is because drinkers would choose to drive home if the party ended early (around 3:00 am), resulting an increase in drunk driving incidents, but they would not choose to drive home if the party ended late. Regarding the abrupt change between 18:00-20:00 and 20:00-22:00, it is believed that after 20:00, parties would end gradually and people would drive when they left the dinner, causing such a break point. Regarding the small peak at the period from 14:00-16:00, it is believed that drinkers would drive home after dinners or work events, resulting in drink driving incidents. Traffic policemen should pay attention to the strict inspection of drunk driving peak time and holidays every night in their work. Police should be deployed at key sections and intersections, and inspection stations should be set up.Reduce the occurrence of drunk driving accidents. 
The number of non-local vehicles being drive in Guangzhou reached 4,550,000 per month at the end of 2013 , and included 300,000 non-local vehicles that have always been used in Guangzhou, with the other being urban transit and peripheral vehicles. Most transit vehicles were freight vehicles, and they had no defined work days and non-work days, which likely affected the difference of drunk-driving rate between work days and non-work days. More than half of the collisions occurred on urban roads and on weekdays during the daytime. A total of 3,333 collisions occurred during 1,252 work days, with a detection rate of drunk driving collisions of $59.8 \%$. A total of 1,653 collisions occurred during 575 non-work days, with a detection rate of drunk driving collisions of $60.9 \%$. Lili Ji et al.indicated that the detection rate of drunk driving of non-local vehicles was 3.197 times as high as that of local vehicles [29]. There were statistical differences in the number of drink driving collisions on work days between 2012 and 2016, and between 2015 and 2016, indicating that drunk driving collisions on work days in 2016 were significantly lower compared to 2012 and 2015.

Regarding accident damage, we found that there were 1.51 times as many drunk driving collisions as non-drunk driving collisions. There were significant differences in the mortality rate and injury rate between drunk driving and non-drunk driving collisions, but the mortality and injury rates in the non-drink driving group were higher than those in the drunk driving group, which was consistent with results reported by Le Li et al [30] $₫$ that is, the casualty rate of collisions caused by drivers with a low blood alcohol concentration $(0 \mathrm{mg} / 100 \mathrm{~mL}<\mathrm{BAC}<20 \mathrm{mg} / 100 \mathrm{~mL})$ were higher than that of drunk driving collisions. It is believed that many people have confidence regarding their mental state, control ability, and reactivity, but in fact these have all been affected by the alcohol[31]. Although they could well avoid nonmoving objects (such as protective fences and border trees), they would not be able to avoid moving objects such as pedestrians and vehicles suddenly appearing, resulting in road traffic collisions with injuries or deaths. When the blood alcohol concentration of the drivers was high (BAC $\geq 20 \mathrm{mg} / 100 \mathrm{~mL}$ ), which significantly reduces reactivity, they could not well avoid non-moving objects (such as protective fences and border trees), and thus it was less likely that a person would be injured, resulting in lower casualty detection rate of drunk driving collisions than that of non-drunk driving collisions.

\section{Conclusion}

Through the analysis time distribution of drunk driving in some districts of Guangzhou, we found that the detection rate of drunk driving at nighttime was 1.86 times as high as that in the daytime, and the detection rate of drunk driving was the highest in February. The detection rate of drunk driving was the highest during the period from 02:00-04:00 (75.9\%), and lowest during the period from 10:00-12:00 (20.0\%), and there was no obvious difference in the periods that collisions occurred between work days and non-work days. Regarding accident damage, there were 1.51 times as many drunk driving collisions as non-drunk driving collisions. The result was indicative that there are different trends of drunk driving collision accidents in different time periods in Guangzhou between 2012 and 2016. we can tighten the intensity of drunk driving inspection so as to prevent road traffic collisions caused by drunk driving. At the same time, the government should step up publicity and education on the hazards of drunk driving to reduce the occurrence of drunk driving Road traffic. 


\section{Declarations}

I declared that this research article is my original work and all concerned bodies are well acknowledged. This manuscript is neither used for fulfillments of academic work nor submitted to other journals elsewhere.

\section{Ethics approval and consent to partcipate}

The study was approved by the ethical review committee of the Southern Medical University of Guangzhou, China. All the information were kept confidentially.

Availability of data and materials

The datasets used and/or analyzed during this study are available from the corresponding author on reasonable request.

\section{Competing interests}

All authors declare that they have no conflicts of interest.

\section{Funding}

This research was financially supported by National Natural Science Foundation of China(No.81673041) and Guangdong Natural Science Foundation of China (No.2017A030313760). Helpful suggestions by anonymous referees are also gratefully acknowledged.

\section{Authors' contributions}

SM and ZHS collaborated in the interpretation of results and the writing of the manuscript. DY was involved in the design of this study and critically reviewed the manuscript. All authors read and approved the final manuscript.

\section{Acknowledgements}

The authors thank the study participants for their contribution to the research.

\section{Author details}

1.Hygiene Detection Center, Guangdong Provincial Key Laboratory of Tropical Disease Research, School of Public Health, Southern Medical University, Guangzhou 510515, China

2. Department of Biostatistics, school of Public Health,Southern Medical University,Guangzhou 510515, China 
Shen Mei, Email: shmei3@126.com

Du Yue, Email: Duyue0524@163.com

Zhou Hua-sheng, Email: 755047101@qq.com

\section{Abbreviations}

WHO World Health Organization

BAC blood alcohol concentration

\section{References}

1. Ning P, Schwebel DC, Huang H, et al. Global Progress in Road Injury Mortality since 2010. PLoS One 2016; 11:e0164560.

2. Peden $M$, Scurfield $R$, Sleet $D$, et al. World report on road traffic injury prevention, World Health Organization Geneva 2004; 10:270-275.

3. Zhang X, Yao H, Hu G, et al. Basic characteristics of road traffic deaths in china. Iran J. Public Health 2013;42: 7-15.

4. Nagata T, Setoguchi S, Hemenway D, et al. Effectiveness of a law to reduce alcohol-impaired driving in Japan. Inj Prev 2008;14:19-23.

5. WHO. Global status report on road safety 2015: supporting a decade of action: summary, 2015.https://www.who.int/violence_injury_prevention/road_safety_status/2015/en/

6. Statistical Communique on national economic and social development of the People's Republic of China in 2016. National Bureau of statistics of the People's Republic of China. 2017. http://www.stats.gov.cn/tjsj/zxfb/201702/t20170228_1467424.html

7. Ogazi C. Edison E. The drink driving situation in Nigeria.Traffic Inj Prev 2012;13(2):115-119.

8. Ngoc LB, Thieng NT, Huong NL.The drink driving situation in Vietnam.Traffic Inj Prev 2012;13(2):109-114

9. Zhang X, Yao H, Hu G, et al. Basic characteristics of road traffic deaths in china. Iran J Public Health 2013;42:7-15.

10. Liu GF, Wu ZL, Liang DH, et al. Association of Alcohol Drinking in Drivers and Risk for Road Motor Vehicle Injury. China Preventive Medicine 2005;6ه2ه囚112-115.

11. Nagata T, Setoguchi S, Hemenway D, et al. Effectiveness of a law to reduce alcohol-impaired driving in Japan. Inj Prev 2008;14:19-23.

12. Asbridge M, Mann RE, Flam-Zalcman R, et al. The criminalization of impaired driving in Canada: assessing the deterrent impact of Canada's first per se law. J Stud Alcohol 2004;65:450-459. 
13. Chang HL, Yeh CC. The life cycle of the policy for preventing road accidents: an empirical example of the policy for reducing drunk driving crashes in Taipei. Accid Anal Prev 2004;36:809-818.

14. Grant DA. A structural analysis of U.S. drunk driving policy. International Review of Law and Economics 2016, 45ه14-22.

15. Li Y, Xie D, Nie G, et al. The drink driving situation in China.Traffic Inj Prev 2012;13:101-108.

16. Jia K, Fleiter J, King M, et al. Alcohol-related driving in China: Countermeasure implications of research conducted in twocities. Accid Anal Prev 2016; 95:343-349.

17. Li Q, He H, Duan L, et al. Prevalence of drink driving and speeding in China: a time series analysis from two cities. Public Health 2017;144S:S15-S22.

18. Zhao A, Chen R, Qi Y, et al. Evaluating the Impact of Criminalizing Drunk Driving on Road-Traffic Injuries in Guangzhou,China: A Time-Series Study. J Epidemiol 2016;26:433-439.

19. Hingson R, Winter M. Epidemiology and consequences of drinking and driving. Alcohol Res Health 2003;27:63-78.

20. Bonilla-Escobar FJ, Herrera-López ML, Ortega-Lenis D, et al. Driving under the influence of alcohol in Cali, Colombia: prevalence and consumption patterns, 2013. Int J Inj Contr Saf Promot 2016; 23:179-88.

21. Sobngwi-Tambekou JL, Brown TG, Bhatti JA. Driving under the influence of alcohol in professional drivers in Cameroon. Traffic Inj Prev 2016;1:73-78.

22. Houwing S, Stipdonk H. Driving under the influence of alcohol in the Netherlands by time of day and day of the week. Accid Anal Pre. 2014;72:17-22.

23. Zivković V, Nikolić S, Lukić V, et al. The effects of a new traffic safety law in the Republic of Serbia on driving under the influence ofalcohol. Accid Anal Prev. 2013;53:161-165.

24. MacLeod KE, Karriker-Jaffe KJ, Ragland DR, et al. Acceptance of drinking and driving and alcoholinvolved driving crashes in California. Accid Anal Prev 2015;81:134-142.

25. 口Threshold and test of blood and expiratory alcohol content in vehicle drivers $\square$ GB 19522-2010 2011. http://www.doc88.com/p-098919248925.html

26. Asbridge M, Mann RE, Flam-Zalcman R, et al. The criminalization of impaired driving in Canada: assessing the deterrent impact of Canada's first per se law. J Stud Alcohol 2004;65:450-459.

27. Chang HL, Yeh CC. The life cycle of the policy for preventing road accidents: an empirical example of the policy for reducing drunk driving crashes in Taipei. Accid Anal Prev 2004;36:809-818.

28. Sattha Riyapan, MD, MPH, Phanthanee Thitichai, MD,et al.Outcomes of Emergency Medical Service Usage in Severe Road Traffic Injury during Thai Holidays. West J Emerg Med 2018; 19(2): 266-275.

29. Ji LL, Zhang M, Yang GP, et al. Drunk driving and its influential factors among motor drivers in Nanjing City. Chinese Journal of Disease Control \& Prevention 2015;19: 35-38.

30. Li L, Hong SJ, Li SH, et al. The Relationship between Road Traffic Accident Injury and Blood Alcohol Concentration of Drivers.Chinese Journal of Forensic Sciences 2013;5: 32-36. 
31. Wu J, Xu H. Driver behavior analysis for right-turn drivers at signalized intersections using SHRP 2 naturalistic driving study data. J Safety Res 2017;63:177-185.

\section{Tables}

Table1 Time distribution of drunk driving and non-drunk driving traffic crashes in some areas of Guangzhou from 2012 to 2016 [n (\%)] 


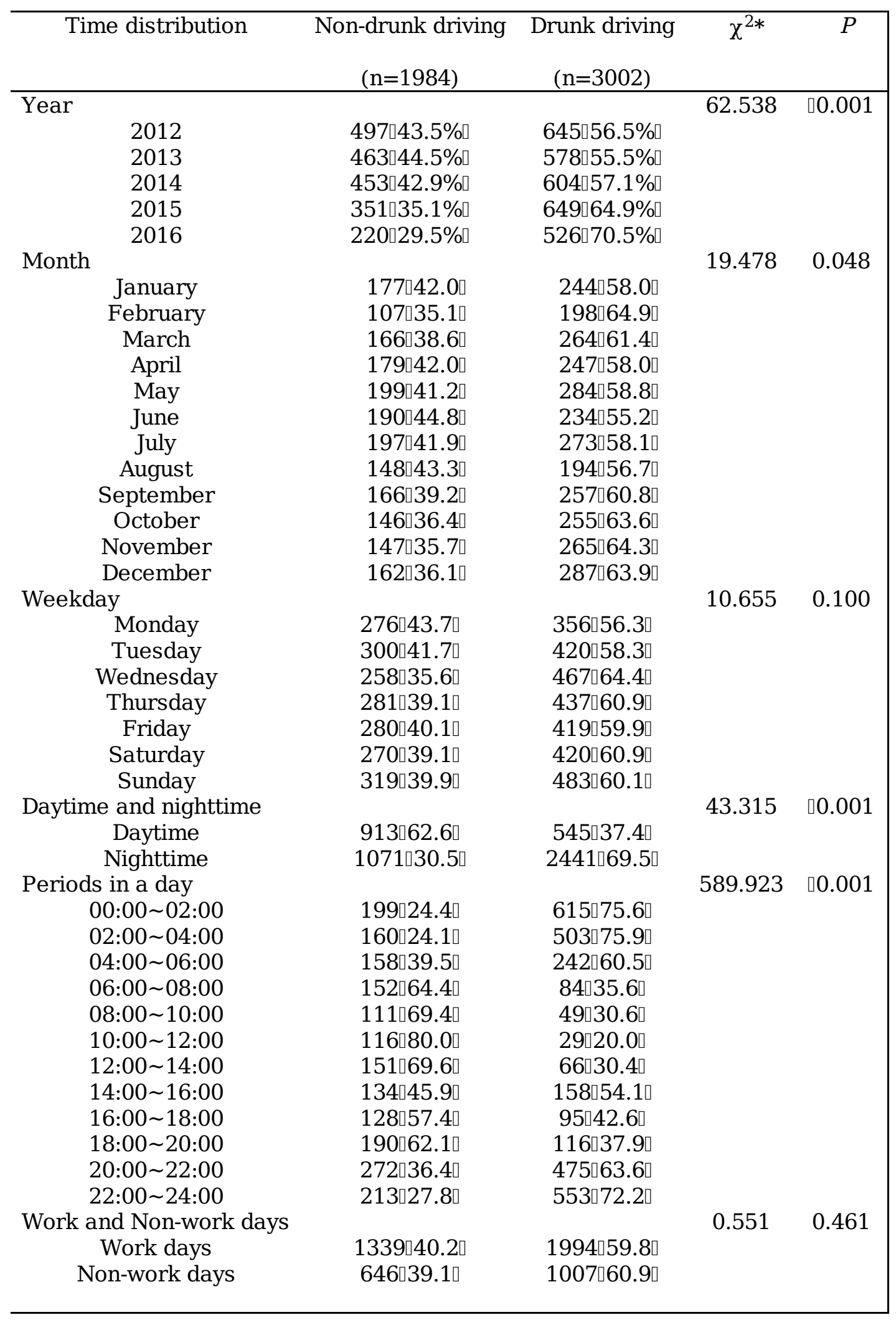

* significant level: alpha $=0.05$.

Table 2. Pairwise comparison of the average monthly number of drunk driving-induced accidents between 2012 and 2016 


\begin{tabular}{ccccccc}
\hline Year & 2013 & 2014 & 2015 & 2016 & $\chi^{2 *}$ & $P$ \\
\hline 2012 & $5.3 \pm 3.208 \mathrm{a}$ & $5.1 \pm 3.208 \mathrm{a}$ & $1.4 \pm 3.208 \mathrm{a}$ & $8.8 \pm 3.208 \mathrm{~b}$ & 2.383 & 0.062 \\
2013 & - & $0.1 \pm 3.208 \mathrm{a}$ & $3.9 \pm 3.208 \mathrm{a}$ & $3.5 \pm 3.208 \mathrm{a}$ & & \\
2014 & - & - & $3.7 \pm 3.208 \mathrm{a}$ & $3.6 \pm 3.208 \mathrm{a}$ & & \\
2015 & - & - & - & $7.4 \pm 3.208 \mathrm{~b}$ & & \\
\hline
\end{tabular}

*significant level: alpha $=0.05 \square$

a The difference was not statistically significant $₫ \mathrm{~b}$ the difference was statistically significant

Table 3. The casualties in some areas in Guangzhou between 2012 and 2016 [n]\%]

\begin{tabular}{ccccc}
\hline Group & Non-drunk driving & Drunk driving & $\chi^{2 *}$ & $P$ \\
\hline Death & $985 \square 49.6 \square$ & $423 \square 14.1 \square$ & 754.249 & $\square 0.001$ \\
Not death & $999 \square 50.4 \square$ & $2579 \square 85.9 \square$ & & \\
Injured & $610 \square 30.7 \square$ & $648 \square 21.6 \square$ & 53.134 & $\square 0.001$ \\
Uninjured & $1374 \square 69.3 \square$ & $2354 \square 78.4 \square$ & & \\
\hline
\end{tabular}

* significant level: alpha $=0.05$.

\section{Figures}

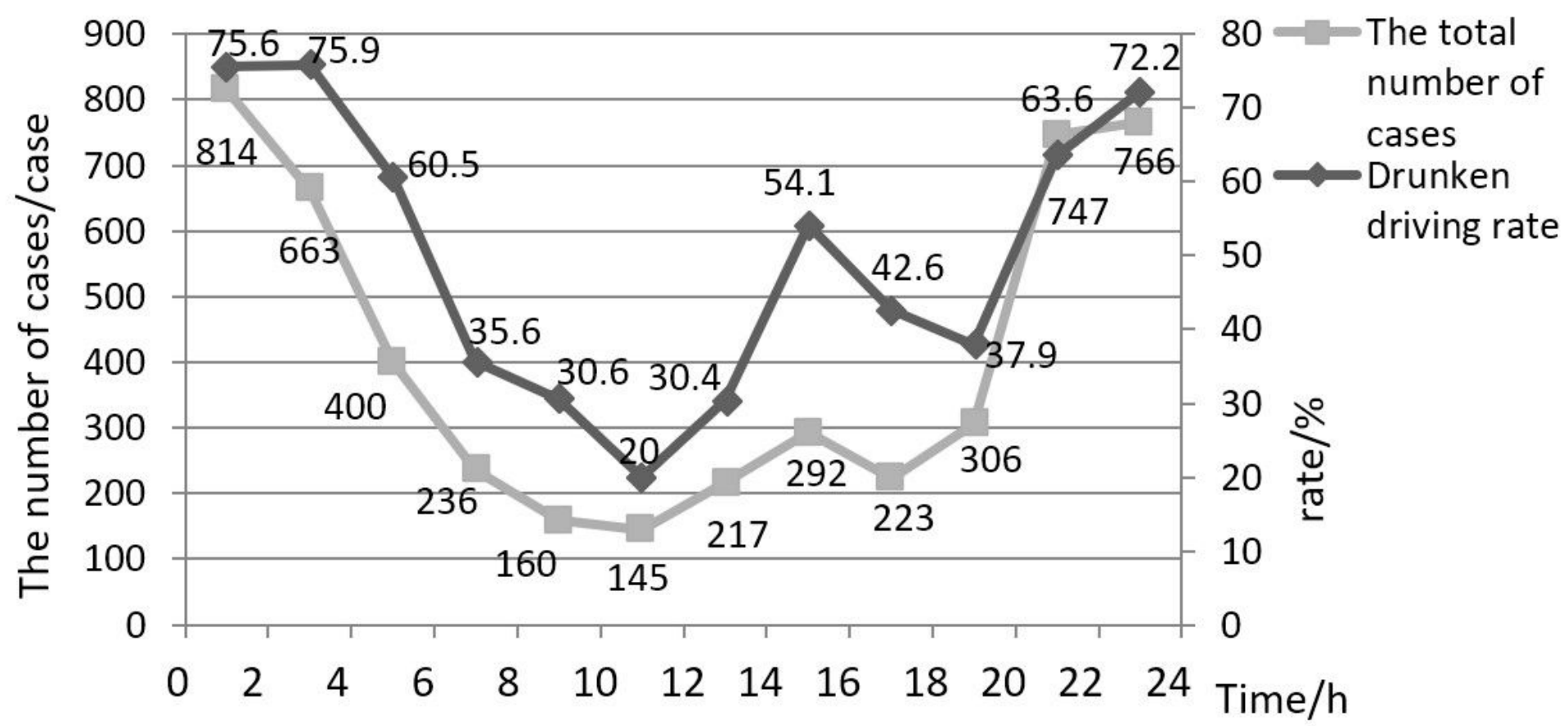

Figure 1 
Temporal dynamics of the drunk driving rate and the total number of accidents during 24 hours

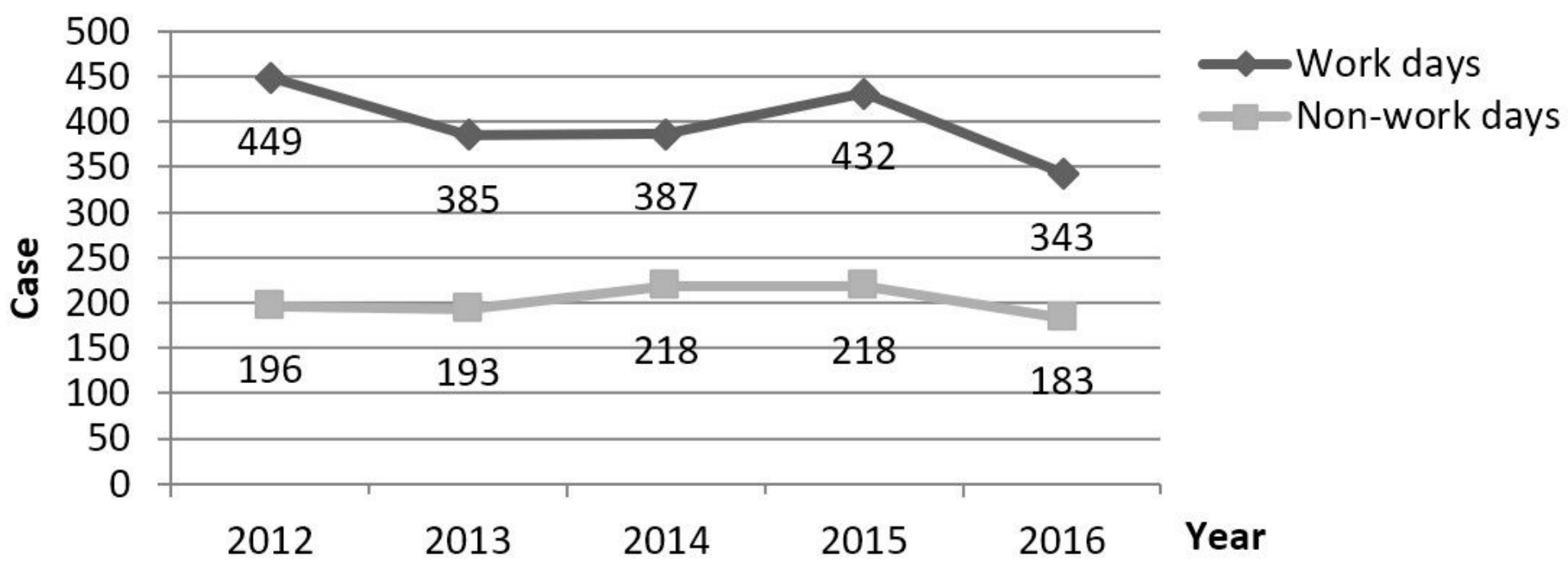

Figure 2

Drunk driving-induced accidents variations in work days and non-work days respectively between 2012 and 2016 